\title{
Impact on energy, sodium and dietary fibre intakes of vegetables prepared at home and away from home in the USA
}

\author{
Biing-Hwan Lin ${ }^{1, *}$, Minh Wendt ${ }^{2}$ and Joanne F Guthrie ${ }^{1}$ \\ ${ }^{1}$ Economic Research Service, US Department of Agriculture, 4th Floor, 355 E Street SW, Washington, \\ DC 20024-3221, USA: ${ }^{2}$ The Office of Minority Health, US Department of Health and Human Services, \\ Rockville, MD, USA
}

Submitted 14 September 2012: Final revision received 15 April 2013: Accepted 13 May 2013: First published online 8 July 2013

\begin{abstract}
Objective: To examine how increasing vegetable consumption from foods prepared at home (FAH) and foods prepared away from home (FAFH) would impact energy, dietary fibre and $\mathrm{Na}$ (sodium) intakes in the USA.

Design: Using data from the 2003-2004 US National Health and Nutrition Examination Survey, dietary intake data from two separate days were fitted with a first-difference (fixed-effects) model. Vegetables consumed from all sources, including mixed foods and juices, were disaggregated and expressed as amounts equivalent to one cup of whole vegetables.

Setting: Nationally representative sample of the US population.

Subjects: Individuals aged 2 years and above reporting $2 \mathrm{~d}$ of dietary intake data in 2003-2004 ( $n$ 7647).

Results: Holding constant the total amount of food consumed, consuming an additional cup of tomatoes and potatoes from FAFH increases energy intake by respectively 1522 and $665 \mathrm{~kJ}$, as compared with 246 and $367 \mathrm{~kJ}$ for FAH. Each additional cup of tomatoes from FAH is associated with an additional $179 \mathrm{mg}$ of $\mathrm{Na}$, compared with $113 \mathrm{mg}$ for FAFH. All vegetable consumption increases fibre intake, except for potatoes and tomatoes from FAFH. Dark green and orange vegetables from FAH add the largest amount of fibre $(1 \cdot 38 \mathrm{~g} / \mathrm{cup})$.

Conclusions: Because US consumers frequently consume vegetables as part of mixed foods that add energy and $\mathrm{Na}$, heavier consumption of vegetables as currently prepared raises the energy content and $\mathrm{Na}$ density of the overall diet. This is particularly true for vegetables prepared away from home.
\end{abstract}

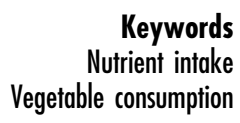

Keywords

Vegetable consumption
'Eat more vegetables' has been a basic part of the US Government's dietary guidance for decades. The general diet and health benefits of vegetables are well documented $^{(1,2)}$. They are major contributors of several under-consumed nutrients; moreover, consumption of fruits and vegetables has been shown to be associated with reduced risks of CVD, certain types of cancer and type 2 diabetes. In addition, vegetables in their natural form are low in energy and $\mathrm{Na}$, and their high dietary fibre content provides non-caloric bulk, promoting a feeling of fullness and satiety. Therefore, eating more vegetables would seem to be an effective strategy for achieving two US priority public health goals: reducing the prevalence of obesity among Americans and reducing $\mathrm{Na}$ intake.

While it seems logical that increasing vegetable consumption would be associated with reduced risk of obesity, the evidence is mixed. Expert reviews of studies examining the relationship between fruit and vegetable consumption and body weight have concluded that the evidence for an obesity-preventing role is weak and inconclusive $^{(1-4)}$. Consequently, the 2010 edition of the
US Dietary Guidelines for Americans provided only a qualified statement that fruits and vegetables may be a useful component of programmes designed to achieve and sustain weight loss ${ }^{(5)}$.

Although the health effects of fruit and vegetable consumption are often studied jointly, there is evidence to suggest that vegetable consumption and fruit consumption may affect body weight differently ${ }^{(6-9)}$. For example, lower BMI (a measure of obesity) among women has been found to be associated with higher fruit consumption but not vegetable consumption ${ }^{(7,8)}$. A plausible explanation is that vegetables as typically eaten by Americans might be higher in energy than the unadorned vegetables presented in dietary guidance. Most vegetables undergo some form of preparation before being consumed, which may add energy. For example, they may be served with a buttery sauce or incorporated into a mixed dish, such as a pasta or pizza dish. With Americans consuming more food prepared away from home, it is possible that different choices away from home also play a role. For example, comparing 
three popular potato products, each $100 \mathrm{~g}$ of baked potatoes (flesh and skin, no salt or sauce), plain and unsalted potato chips, and restaurant French fries on average contain 389, 2243 and $1222 \mathrm{~kJ}$, respectively ${ }^{(10)}$. The typical choice between products differs by the location where foods are obtained and eaten. The bulk of potato chips are consumed at home, whereas French fries are consumed mainly at restaurants. Similarly, although vegetables are naturally low in $\mathrm{Na}$, salt and other Na-containing ingredients may be added, raising their Na content. Fruit, as consumed by Americans, contributes only $0 \cdot 1 \%$ of $\mathrm{Na}$ to the diet, but vegetables contribute $9 \cdot 3 \%$, and vegetable-containing mixed dishes contribute still more ${ }^{(11)}$. Clearly, how and where we eat vegetables can greatly affect their energy and nutrient contribution to the diet, especially considering the fact that almost one-third of US consumers' energy intake comes from restaurants, fast food and other locations outside the home ${ }^{(12)}$.

The purpose of the present study is to examine current US patterns of vegetable consumption, at home and away from home, and to consider the dietary consequences of consuming more vegetables in a manner that follows current American eating patterns. The nutritional outcomes of interest are energy, dietary fibre and $\mathrm{Na}$ intakes. We focus on these dietary components because of their relevance to current priority recommendations for improvement in diet and health. The US Government's Dietary Guidelines for Americans $^{(5,13)}$ emphasize the need to maintain energy balance over time to achieve and sustain a healthy weight, point out the persistent under-consumption of dietary fibre over past decades and emphasize the need to moderate Na intake. As low-energy, high-fibre, low-Na foods in their natural forms, increasing vegetable consumption would seem an effective way to improve diet with respect to these recommendations.

\section{Methods}

We use dietary recall data from the 2003-2004 National Health and Nutrition Examination Survey (NHANES), conducted jointly by the Centers for Disease Control and Prevention, US Department of Health and Human Services and the Agricultural Research Service, US Department of Agriculture (USDA) ${ }^{(14)}$. NHANES surveyed a nationally representative sample of individuals of all ages and oversampled persons aged 12-19 years and 60+ years, AfricanAmericans, Mexican-Americans, low-income persons and pregnant women. A computerized Automated Multiple-Pass Method was used to collect $24 \mathrm{~h}$ dietary recall data for two non-consecutive days ${ }^{(15)}$. The first-day data were collected in person and the second-day data were collected via telephone interview.

NHANES respondents report the foods and their amounts consumed. Nutrient intakes are derived from food intakes using the USDA's Food and Nutrient Database for Dietary Studies ${ }^{(10)}$. We focus on energy, fibre and $\mathrm{Na}$ intakes as the dietary outcome variables in the present study. We express fibre and $\mathrm{Na}$ intakes in terms of density (the amount of fibre and $\mathrm{Na}$ from foods that contain $4184 \mathrm{~kJ}$ or $1000 \mathrm{kcal}$ ) to measure the dietary impacts of consuming vegetables distinguished by type and location. The density approach addresses the quality of an individual's diet and is used by the USDA as a key measure underlying the development of the 2005 Healthy Eating Index $^{(16)}$, which measures how well an individual's diet adheres to US Federal dietary guidance.

Foods may contain vegetables as the sole ingredient or as a part of the food. Although dietary advice makes broad recommendations for total amount of vegetables consumed from all forms, it can be difficult to estimate total vegetable consumption because vegetables can be served in many forms - as solids, juices, pureed and made into sauces, or incorporated into mixed dishes. To aggregate all forms consumed, we use the 2003-2004 MyPyramid Equivalents Database (MPED) ${ }^{(17)}$. The MPED separates foods as consumed into their food group components (e.g. separating a beef stew with vegetables into meat and vegetable components) and then expresses the contribution of each component to food group consumption using a standard unit. Vegetable consumption is expressed as cups, with one cup of raw or cooked vegetables established as the standard. If a vegetable is processed into a more concentrated form before consumption (such as sun-dried tomatoes or a tomato paste), an amount that is equivalent to the solids in the nonconcentrated form is defined as a 'cup-equivalent.' Cups and cup-equivalents are summed to a total amount of vegetables from all sources. At the time our analysis was conducted, the 2003-2004 MPED was the most up-todate database that could be used to derive complete vegetable intake data, which limited us to the 2003-2004 NHANES data.

In addition to reporting the food and the amount consumed, NHANES respondents also report where the food was obtained and eaten. We define home and awayfrom-home foods based on where the food is obtained, not where it is eaten. Food at home (FAH) is purchased at a retail store, such as a grocery store, a convenience store or a supermarket. Food away from home (FAFH) is purchased mainly from food-service establishments, schools and other places, where foods are typically ready to eat and consumed as is. The NHANES sample size is 5000 for each year. After excluding children under 2 years of age and those who did not have complete $2 \mathrm{~d}$ intake data, there are 7647 individuals included in our study.

For our analyses, we examine vegetable consumption disaggregated into subgroups defined on the basis of nutritional interest and importance in US consumption patterns. According to the 2003-2004 NHANES intake data, Americans consumed an average of 1.5 cups of 
Table 1 Daily intake of vegetables by type and source in a nationally representative sample of the US population ( $n$ 7647)

\begin{tabular}{lccc}
\hline & \multicolumn{3}{c}{ Cups/d } \\
\cline { 2 - 4 } & Total & At home & Away home \\
\hline All vegetables* $^{*}$ & 1.50 & 0.95 & 0.55 \\
Dark green and oranget & 0.16 & 0.12 & 0.04 \\
Potatoes & 0.40 & 0.25 & 0.14 \\
Tomatoes & 0.37 & 0.22 & 0.15 \\
Others & 0.59 & 0.37 & 0.23 \\
\hline
\end{tabular}

Source: National Health and Nutrition Examination Survey 2003-2004 *Exclude legumes, which can be treated as meat alternate.

tDark green vegetables include arugula, beet greens, broccoli, chard, chicory, cilantro, collar greens, dandelion greens, endive, escarole, grape leaves, kale, lambs quarters, mustard greens, parsley, poke greens, pumpkin leaves, romaine lettuce, spinach, sweet potato leaves, taro leaves, turnip greens and watercress. Orange vegetables include calabaza, carrots, pumpkin, sweet potato, winter squash and yams.

$\ddagger$ Other vegetables include starchy vegetables and others. Potatoes are separated from starchy vegetables that include black-eyed peas (not dried), breadfruit, cassava, corn, cowpeas (not dried), dasheen, green peas, hominy, jicama, lima beans (immature), parsnips, pigeon peas, rutabaga, tannier, taro and yam beans. Tomatoes are separated from others that include algae, aloe vera juice, artichoke, asparagus, balsam-pear pods, bamboo shoots, bean and alfalfa sprouts, broccoflower, beets, Brussels sprouts, cabbage, cactus, capers, cauliflower, celery, chayote, Chinese cabbage, chives, christophine, chrysanthemum, coriander, cucumber, eggplant, garlic, ginger root, green beans, horseradish, leek, lettuce, lotus root, mushrooms, noplaes, okra, olives, onions, oriental radishes, palm hearts, peppers, pimiento, radicchio, radishes, seaweed, snow peas, summer squash, swamp cabbage, tomatillos, turnips, water chestnuts, wax beans, wax gourd, winter melon and zucchini.

The above listings of vegetables come from the US Department of Agriculture's Pyramid Serving Data available at http://www.ars.usda.gov/ SP2UserFiles/Place/12355000/pdf/3yr_py.pdf (accessed March 2013).

vegetables/d from all sources (Table 1 ). There are five major vegetable groups (dark green, orange, starchy, legumes, others) specified in the 2003-2004 MPED. Potatoes and tomatoes are the most consumed vegetables in the USA; therefore, although food guidance systems assign potatoes to the starchy vegetable group and tomatoes to the 'others' group, we examine their consumption separately. Dark green and orange vegetables receive special emphasis in US dietary guidance as nutritious but under-consumed vegetables. With 0.09 cup of dark green vegetables and 0.07 cup of orange vegetables being consumed daily; together these groups accounted for about $10 \%$ of total US vegetable consumption (Table 1). Because of the low consumption amounts, we combine dark green and orange vegetables into one category. In the present study, legumes are excluded from the vegetable category because they are otherwise classified in some food grouping systems, including DASH (Dietary Approaches to Stop Hypertension) ${ }^{(18)}$ which is cited in the Dietary Guidelines for Americans $^{(5)}$ as a healthful eating pattern.

While dark green and orange vegetables are highly recommended, but under-consumed, potatoes and tomatoes are the most important vegetables in terms of actual consumption in the USA ${ }^{(19)}$. As such, their nutrient content as consumed has a large impact on the overall nutrient contribution of vegetables to the diet. Together they made up over half $(51 \%)$ of total vegetable consumption in 2003-2004. In addition, both are served in a wide range of forms and are popular at home and away from home, suggesting that their sources and the forms in which they are consumed can have important influences on diet quality. Potatoes and tomatoes are treated as two separate categories in our analysis. All other vegetables, taken together, make up about $40 \%$ of vegetable consumption and are aggregated into an 'other vegetables' category. Vegetables that fall under each category are listed in footnotes in Table 1.

\section{Statistical analysis}

To examine the effect of vegetable intakes by type and source on energy, dietary fibre and $\mathrm{Na}$ intakes, we employ a first-difference (fixed-effects) regression model $^{(20)}$ in which dietary outcomes (energy, fibre and $\mathrm{Na}$ ) are the dependent variables and the explanatory variables include eight vegetable intake variables: four vegetable categories (dark green and orange vegetables, potatoes, tomatoes, other vegetables), with each category disaggregated into at-home and away-from-home consumption. The regression coefficients measure how energy, fibre and $\mathrm{Na}$ intakes change in response to different vegetable intakes. With two non-consecutive days of data being reported by NHANES respondents, dietary outcomes and vegetable intakes are represented by the difference between day 1 and day 2 for each NHANES respondent, hence the regression model is called the first difference.

The first-difference model is particularly suitable for studies when multiple data points are collected for each study subject. An ordinary least squares regression that uses a single dietary outcome variable (either a $1 \mathrm{~d}$ intake or the mean of multiple daily intakes) can only control for personal characteristics such as gender, age, etc. that are available in the data set. The first-difference model makes use of repeated dietary measures to control for other, unmeasured personal characteristics that may influence dietary outcomes; for example, greater or lesser preference for vegetables or salty foods. Because many of these unobserved individual characteristics are constant over a short period of time (the two intake-recall days are 7-10 d apart in NHANES), the first-difference model is effective in addressing bias that would otherwise result from unobserved characteristics ${ }^{(21)}$.

The model is also effective in addressing the problem of reporting bias. It is known that dietary recalls are subject to under-reporting bias, even though underreporting has been decreased in the NHANES by implementation of the Automated-Multiple-Pass Method ${ }^{(15)}$. NHANES respondents typically report a lower consumption, in volume and energy, in the second recall than the first-day recall, suggesting the existence of under-reporting bias associated with the progression of dietary recall when intake data are collected for multiple days. This under-reporting bias in dietary recall understates food consumption, but because individuals' nutrient intakes 
and food intakes are matched, estimating changes in nutrient intakes from changes in vegetable intakes by fitting a fixed-effects model is free from under-reporting (or over-reporting) bias.

The survey commands available in the statistical software package Stata release 10 are used to incorporate the complex survey design employed in NHANES and sample weights into the estimation of the first-difference model. In addition to the eight consumption variables for vegetables, we also include two variables to control for the total amount of food consumed (in grams) and whether the intake day is a weekday or weekend day. Unlike personal characteristics, these two variables can vary within a short time period so they must be taken into account. Eating more (less) than the usual amount of foods in a day is likely to increase (decrease) energy intake for the day. It is typical that an individual's food intake varies between weekdays and weekend days. Either the amount of food or the energy consumed can be used to control for total food consumption; we use food amount (grams) because energy intake is a dietary outcome variable in the first-difference model.

\section{Results}

Descriptive statistics for the dependent and independent variables (expressed in first differences and averages of the two days) are reported in Table 2. On average, the second-day intake is lower than the first-day intake by $356 \mathrm{~kJ}$ of energy ( $4 \%$ of daily intake of $8989 \mathrm{~kJ}$ ) and $148 \mathrm{~g}$ (7\%) of food intake. The descriptive statistics suggest that on average the second-day diet is better than the first-day diet with respect to dietary fibre and $\mathrm{Na}$ intakes. A larger portion of vegetables was consumed at home than away from home; this is true for all four vegetable groups. On average, more vegetables were consumed at home on the second recall day than the first day; whereas the opposite is observed for vegetables consumed away from home.

Regression results are summarized in Table 3. The results indicate that, controlling for the total amount of food consumed, when US consumers eat more vegetables their energy intakes increase as well. This finding holds for all vegetable types and sources, although effects on energy are stronger for some types of vegetables than others, and, except in the case of dark green and orange

Table 2 Averages of daily and first differences of dietary outcomes and intakes; nationally representative sample of the US population ( $n$ 7647)

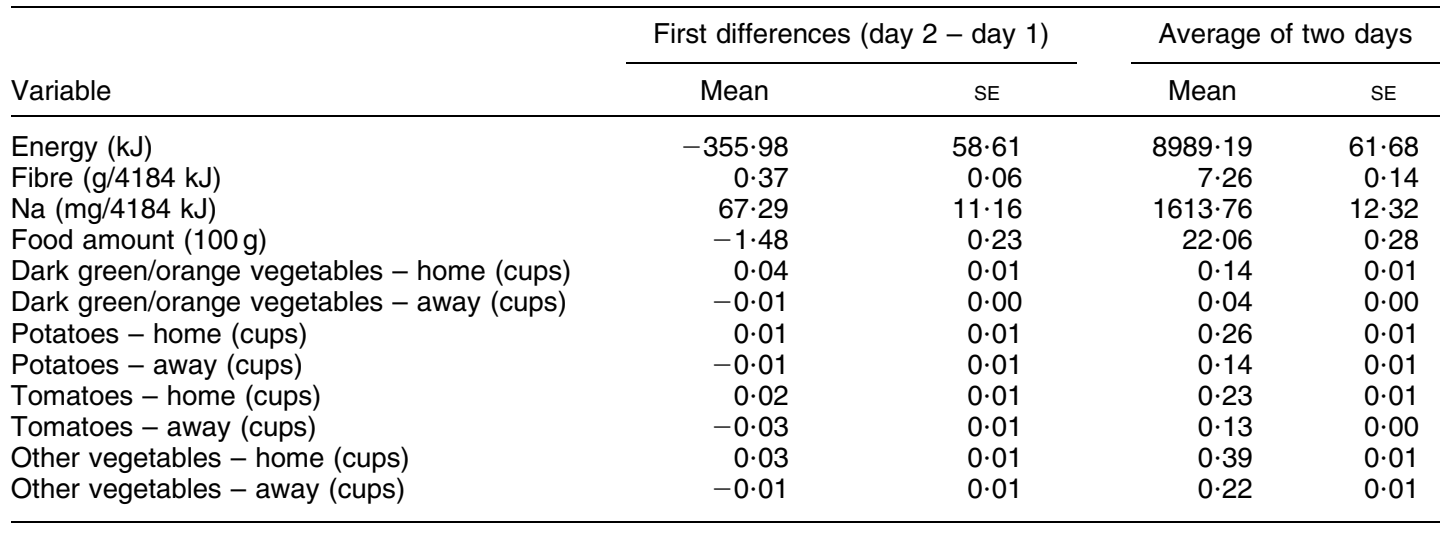

Source: National Health and Nutrition Examination Survey 2003-2004.

Table 3 Empirical results of the first-difference model; nationally representative sample of the US population ( $n$ 7647)

\begin{tabular}{|c|c|c|c|c|c|c|c|c|c|}
\hline & \multicolumn{3}{|c|}{ Energy (kJ) } & \multicolumn{3}{|c|}{ Fibre (g) } & \multicolumn{3}{|c|}{$\mathrm{Na}(\mathrm{mg})$} \\
\hline & $\beta$ & SE & $P$ & $\beta$ & SE & $P$ & $\beta$ & SE & $P$ \\
\hline Food amount $(\mathrm{g})$ & $236 \cdot 84$ & $7 \cdot 18$ & 0.00 & -0.05 & $0 \cdot 01$ & 0.00 & $-8 \cdot 02$ & $2 \cdot 03$ & 0.00 \\
\hline Dark green/orange vegetables - home (cups) & $332 \cdot 84$ & $117 \cdot 26$ & 0.01 & $1 \cdot 38$ & $0 \cdot 26$ & 0.00 & $-55 \cdot 80$ & 28.49 & 0.07 \\
\hline Dark green/orange vegetables - away (cups) & $124 \cdot 06$ & $337 \cdot 17$ & $0 \cdot 72$ & $1 \cdot 07$ & 0.32 & 0.01 & $186 \cdot 24$ & $125 \cdot 75$ & $0 \cdot 16$ \\
\hline Potatoes - home (cups) & $366 \cdot 70$ & $86 \cdot 56$ & 0.00 & $0 \cdot 30$ & 0.08 & 0.00 & $-52 \cdot 03$ & $23 \cdot 12$ & 0.04 \\
\hline Potatoes - away (cups) & $665 \cdot 35$ & $157 \cdot 61$ & 0.00 & 0.08 & $0 \cdot 10$ & $0 \cdot 43$ & $-75 \cdot 77$ & $35 \cdot 24$ & 0.05 \\
\hline Tomatoes - home (cups) & $245 \cdot 64$ & $117 \cdot 05$ & 0.05 & $0 \cdot 86$ & 0.09 & 0.00 & $178 \cdot 88$ & $18 \cdot 16$ & 0.00 \\
\hline Tomatoes - away (cups) & $1521 \cdot 76$ & $159 \cdot 19$ & 0.00 & $0 \cdot 25$ & $0 \cdot 29$ & $0 \cdot 40$ & $113 \cdot 28$ & $45 \cdot 72$ & 0.03 \\
\hline Other vegetables - home (cups) & $67 \cdot 74$ & $93 \cdot 78$ & $0 \cdot 48$ & $1 \cdot 14$ & 0.07 & $0 \cdot 00$ & $74 \cdot 71$ & $17 \cdot 58$ & 0.00 \\
\hline Other vegetables - away (cups) & $99 \cdot 33$ & $102 \cdot 22$ & $0 \cdot 35$ & 0.49 & $0 \cdot 12$ & $0 \cdot 00$ & $91 \cdot 30$ & $28 \cdot 59$ & 0.01 \\
\hline Weekend & $285 \cdot 28$ & $134 \cdot 90$ & 0.05 & -0.66 & $0 \cdot 19$ & 0.00 & $-25 \cdot 04$ & $21 \cdot 21$ & $0 \cdot 26$ \\
\hline Constant & $-65 \cdot 16$ & $65 \cdot 56$ & $0 \cdot 34$ & 0.41 & 0.08 & 0.00 & $65 \cdot 35$ & $15 \cdot 87$ & 0.00 \\
\hline$R^{2}$ & 0.47 & & & $0 \cdot 11$ & & & 0.06 & & \\
\hline
\end{tabular}

Source: National Health and Nutrition Examination Survey 2003-2004. 
Table 4 Top ten tomato-containing foods by source - shares of consumption and energy and nutrient density; nationally representative sample of the US population ( $n$ 7647)

\begin{tabular}{|c|c|c|c|c|c|c|}
\hline \multirow[b]{2}{*}{ Name of food } & \multicolumn{2}{|c|}{ Share of total ${ }^{*}$} & \multicolumn{2}{|c|}{ Energy per cup } & \multirow{2}{*}{$\begin{array}{c}\text { Fibre density } \\
(\mathrm{g} / 4184 \mathrm{~kJ})\end{array}$} & \multirow{2}{*}{$\begin{array}{l}\text { Na density } \\
\text { (mg/4184 kJ) }\end{array}$} \\
\hline & Cups (\%) & Energy (\%) & (kJ/cup) & (kcal/cup) & & \\
\hline \multicolumn{7}{|l|}{ Top ten at-home consumption } \\
\hline Tomatoes, raw + & $22 \cdot 02$ & $1 \cdot 37$ & $134 \cdot 85$ & $32 \cdot 23$ & $66 \cdot 63$ & $282 \cdot 25$ \\
\hline Spaghetti with tomato and meat sauce & $12 \cdot 59$ & $13 \cdot 41$ & $2306 \cdot 60$ & $551 \cdot 29$ & $7 \cdot 48$ & $2535 \cdot 85$ \\
\hline Spaghetti with tomato sauce, meatless & $7 \cdot 31$ & $4 \cdot 62$ & $1367 \cdot 96$ & $326 \cdot 95$ & $9 \cdot 63$ & $1921 \cdot 29$ \\
\hline Spanish rice & $3 \cdot 46$ & $1 \cdot 81$ & $1132 \cdot 86$ & $270 \cdot 76$ & $13 \cdot 25$ & 3383.05 \\
\hline Tomato and vegetable juice & $3 \cdot 07$ & $0 \cdot 26$ & $184 \cdot 60$ & $44 \cdot 12$ & $33 \cdot 85$ & $14971 \cdot 60$ \\
\hline Salsa, red, cooked, not home-made & $3 \cdot 04$ & $0 \cdot 36$ & $258 \cdot 74$ & $61 \cdot 84$ & $60 \cdot 05$ & $22362 \cdot 15$ \\
\hline Spaghetti sauce, meatless & $2 \cdot 76$ & 0.52 & $403 \cdot 88$ & $96 \cdot 53$ & $5 \cdot 53$ & $6487 \cdot 49$ \\
\hline Chilli con carne with beans & $2 \cdot 54$ & $2 \cdot 71$ & $2311 \cdot 53$ & $552 \cdot 47$ & $25 \cdot 94$ & $3921 \cdot 66$ \\
\hline Pizza with meat, thin crust & $2 \cdot 45$ & $5 \cdot 89$ & $5207 \cdot 53$ & $1244 \cdot 63$ & $5 \cdot 22$ & $2488 \cdot 41$ \\
\hline Pasta with tomato sauce and meat/meatballs, canned & 1.91 & $1 \cdot 35$ & $1528 \cdot 46$ & $365 \cdot 31$ & $26 \cdot 19$ & $4057 \cdot 93$ \\
\hline \multicolumn{7}{|l|}{ Top ten away-from-home consumption } \\
\hline Tomatoes, rawt & $16 \cdot 57$ & 0.49 & $135 \cdot 44$ & $32 \cdot 37$ & $66 \cdot 24$ & $284 \cdot 50$ \\
\hline Pizza with meat, thin crust & $10 \cdot 81$ & $12 \cdot 30$ & 5211.09 & $1245 \cdot 48$ & $5 \cdot 23$ & $2489 \cdot 38$ \\
\hline Pizza with meat, thick crust & $7 \cdot 60$ & $12 \cdot 65$ & $7621 \cdot 45$ & $1821 \cdot 57$ & $5 \cdot 52$ & $2129 \cdot 44$ \\
\hline Spaghetti with tomato and meat sauce & $5 \cdot 14$ & $2 \cdot 59$ & $2306 \cdot 60$ & $551 \cdot 29$ & $7 \cdot 47$ & $2536 \cdot 18$ \\
\hline Spaghetti with tomato sauce, meatless & $4 \cdot 09$ & $1 \cdot 22$ & $1367 \cdot 71$ & $326 \cdot 89$ & $9 \cdot 59$ & $1921 \cdot 72$ \\
\hline Salsa, red, cooked, not home-made & $3 \cdot 34$ & $0 \cdot 19$ & $257 \cdot 99$ & $61 \cdot 66$ & $59 \cdot 79$ & $22425 \cdot 57$ \\
\hline Pizza with meat and vegetables, thin crust & $3 \cdot 12$ & $3 \cdot 73$ & $5487 \cdot 23$ & $1311 \cdot 48$ & $6 \cdot 90$ & $2523 \cdot 60$ \\
\hline Cheese pizza, thin crust & $2 \cdot 79$ & $4 \cdot 21$ & $6912 \cdot 34$ & $1652 \cdot 09$ & $6 \cdot 84$ & $1908 \cdot 05$ \\
\hline Spanish rice & $2 \cdot 32$ & 0.58 & $1150 \cdot 64$ & $275 \cdot 01$ & $13 \cdot 11$ & $3327 \cdot 25$ \\
\hline Cheese pizza, thick crust & $2 \cdot 27$ & $3 \cdot 29$ & $6635 \cdot 66$ & $1585 \cdot 96$ & $7 \cdot 20$ & $1993 \cdot 94$ \\
\hline Overall nutritional value for at-home consumption & & & $2164 \cdot 89$ & $517 \cdot 42$ & $12 \cdot 04$ & $3036 \cdot 49$ \\
\hline Overall nutritional value for away-from-home consumption & & & $4584 \cdot 16$ & $1095 \cdot 64$ & $7 \cdot 27$ & $2446 \cdot 20$ \\
\hline
\end{tabular}

Source: National Health and Nutrition Examination Survey 2003-2004.

${ }^{*}$ Shares are expressed in terms of total tomatoes and energy consumed at and away from home.

tRaw tomatoes are fresh and can be consumed as is or as part of a mixture, such as salads or hamburgers with tomatoes.

vegetables, are stronger for vegetables prepared away from home (FAFH).

For potatoes, the most highly consumed vegetable, an additional one-cup serving of potatoes prepared at home (FAH) adds $367 \mathrm{~kJ}$, whereas an additional cup of FAFH potatoes adds $665 \mathrm{~kJ}$. These differences can be attributed to the form in which potatoes are consumed, with French fries $(2079 \mathrm{~kJ} / \mathrm{cup})$ the most common form of FAFH potatoes.

For tomatoes, the second most commonly consumed vegetable, energy intake increases by $1522 \mathrm{~kJ}$ for each additional cup of tomatoes from FAFH, more than six times the energy obtained when consuming one cup of FAH tomatoes $(246 \mathrm{~kJ})$. Identification of the most commonly consumed tomato-containing foods at home $v$. away from home explains this difference (Table 4). Raw tomatoes, the least energy-dense form consumed, have a larger share of FAH tomato, whereas FAFH tomato is more commonly consumed as a part of higher-energy mixed dishes, in particular pizza. With five types of pizza and two types of pasta among the top ten tomato-containing foods (Table 4), it is clear that much of the tomatoes eaten by US consumers is in the form of sauces and tomato pastes used in mixed dishes.

Eating more tomatoes both from FAH and FAFH also contributes to a higher total $\mathrm{Na}$ intake, as much as $179 \mathrm{mg} / 4184 \mathrm{~kJ}$ for each additional cup of tomatoes prepared at home. Although raw tomatoes are low-Na foods, processed tomato products typically contain large amounts of $\mathrm{Na}$ and they are ingredients used in the popular tomato-containing dishes at home and away from home (Table 4). For example, canned tomato sauce, according to USDA nutrient data, typically contains $1284 \mathrm{mg} \mathrm{Na} /$ cup $^{(10)}$. Eating more 'other' vegetables at home and away from home also contributes to higher $\mathrm{Na}$ intake, but the effect is not as strong as with tomatoes. Eating more potatoes either at home or away from home was associated with lower $\mathrm{Na}$ intake, as was eating more home-prepared dark green and orange vegetables.

All categories of vegetable consumption contribute positively to dietary fibre intake, but when vegetable types and sources are examined separately, the contributions are not significant for potatoes and tomatoes from FAFH. Dark green and orange vegetables as well as 'other' vegetables from FAH consumption add the largest amount of dietary fibre to our diet $(1.38$ and $1.14 \mathrm{~g}$ per $4184 \mathrm{~kJ}$, respectively), followed by dark green and orange vegetables from FAFH $(1 \cdot 07 \mathrm{~g} / 4184 \mathrm{~kJ})$.

\section{Discussion}

Given the numerous health benefits associated with their consumption, eating more vegetables has been a mainstay of US Federal dietary guidance for decades. Consistent with previous findings ${ }^{(1)}$, NHANES data indicate 
that average vegetable intakes of US consumers fall below dietary guidelines' recommendations. Increased consumption of vegetables, with their naturally low energy and $\mathrm{Na}$ densities and high amounts of dietary fibre, would be expected to improve the nutritional profile of the overall diet. However, the results of the present study indicate that if US consumers were to increase their vegetable intake by eating more of the vegetable-containing foods they currently consume, it would result in higher energy intakes and $\mathrm{Na}$ densities.

Examination of the relative contributions of vegetable intakes by type and source indicates that the form in which vegetables are typically consumed is responsible for these results. Note that our analysis considers all vegetable intakes, including vegetables eaten as is; vegetables prepared with additional ingredients such as butter, cooking oil, cheese or salt; and vegetables used as ingredients in mixed foods, such as raw tomatoes in salads and tomato sauce in pizzas and pastas. So that, as part of eating an additional cup of a vegetable, one would eat additional amounts of other ingredients that went into its preparation.

Tomato consumption vividly demonstrates the impact of the form in which the vegetable is consumed. Raw tomatoes are low in energy and $\mathrm{Na}$ and high in dietary fibre and are still the single most popular tomato form in Americans' diets, both at home and away from home. However, as a very versatile product, tomatoes have been processed into a variety of forms and used as ingredients in a variety of foods. Pizzas and spaghetti are two popular tomato-containing foods consumed in the USA, accounting for $35 \%$ of total tomato consumption during 2003-2004. In contrast to raw tomatoes, such foods are more energy dense, lower in dietary fibre and higher in $\mathrm{Na}$. These products are popular both at home and away; however, they are a particularly large share of the tomato obtained from food prepared away from home. Similarly, fried potatoes are the most common form eaten away from home. The US Dietary Guidelines for Americans recommend a low-energy-density diet that is rich in dietary fibre; unfortunately vegetables prepared away from home do not significantly increase the fibre density of the diet, as do vegetables prepared at home. Eating more tomatoes and potatoes in the forms Americans currently eat them, while keeping constant the overall volume of food eaten, will in fact increase energy intake, not reduce it, and may not be effective in increasing dietary fibre intake and reducing $\mathrm{Na}$ intake.

Current findings support the emphasis placed on increasing consumption of dark green and orange vegetables. On a per-cup basis, their consumption has the biggest impact of any vegetable group on the dietary fibre density of home foods; and among away-from-home vegetables, they were also the group with the highest dietary fibre density. Their at-home consumption was also associated with decreased $\mathrm{Na}$ density, relative to tomatoes and other vegetables.
These results highlight the need for nutrition education and labelling efforts that go beyond the basic advice to eat more vegetables. US consumers cannot just eat more of their favourite forms of vegetable-containing foods, but instead need to eat different vegetables - more of the dark green and orange vegetables urged by nutrition experts and eat their favourites, potatoes and tomatoes, in different ways that come with less added energy and less $\mathrm{Na}$.

Advice on home preparation could be useful, as could development of improved food products. The US Institute of Medicine ${ }^{(11)}$ has identified reduction in the Na content of processed foods such as tomato sauce as a key strategy for meeting dietary guidelines for $\mathrm{Na}$ intake. Nutrition information on both home and restaurant foods may also assist consumers in choosing healthier vegetablecontaining foods. While there might be a market advantage in promoting the vegetable content of mixed foods such as pizzas and pastas and downplaying the energy and $\mathrm{Na}$ consumed as part of obtaining a serving of vegetables from these foods, accurate nutrition labelling would provide the consumer with complete, balanced information. Nutrition labelling on packaged foods has been required in the USA since the mid-1990s.

Similarly, nutrition information can be valuable when eating out. As part of the Patient Protection and Affordable Care Act, energy (calorie) information on menus ('menu labelling') has been mandated in the USA for chain restaurants with more than twenty outlets nationwide. Besides informing consumers, labelling may encourage restaurants to reformulate or develop healthier items. In anticipation of menu labelling, one restaurant group reduced the fat content of the toppings on its 'signature salad', resulting in a $38 \%$ energy reduction ${ }^{(22)}$. Such changes in the choices available to consumers, coupled with increased awareness of the health benefits of vegetables, may lead to achievement of the goals of dietary advice targeting increased vegetable consumption.

\section{Acknowledgements}

Sources of funding: B.-H.L. and J.F.G. are respectively an economist and a nutritionist at the Economic Research Service, USDA and M.W. is a policy analyst with US Department of Human and Health Services. The views expressed in this study are those of the authors and cannot be attributed to the US Department of Agriculture or the US Department of Health and Human Services. The authors are employees of the US Government and the project was entirely funded by the US Government. Conflicts of interest: There is no conflict of interest to report. Ethics: Ethical approval was not required. Authors' contributions: B.-H.L. conceptualized the research and worked with J.F.G. to conduct descriptive analyses and prepare the manuscript. M.W. prepared the data and estimated the fixed-effects model. No seniority in authorship is assigned. 


\section{References}

1. Dietary Guidelines Advisory Committee (2011) Report of the Dietary Guidelines Advisory Committee on the Dietary Guidelines for Americans, 2010. A report prepared for the USDHHS and USDA. Washington, DC: USDA, Agricultural Research Service.

2. Dietary Guidelines Advisory Committee (2005) Report of the Dietary Guidelines Advisory Committee on the Dietary Guidelines for Americans, 2005. A report prepared for the USDHHS and USDA. Washington, DC: USDA, Agricultural Research Service.

3. Ledoux TA, Hingle MD \& Baranowski T (2010) Relationship of fruit and vegetable intake with adiposity: a systematic review. Obes Rev 12, 1-8.

4. Tohill BC, Seymour J, Serdula M et al. (2004) What epidemiologic studies tell us about the relationship between fruit and vegetable consumption and body weight. Nutr Rev 62, 365-374.

5. US Department of Health and Human Services \& US Department of Agriculture (2011) Dietary Guidelines for Americans, 2010, 7th ed. Washington, DC: USDHHS and USDA; available at http://www.dietaryguidelines.gov

6. Field AE, Gillman MW, Rosner B et al. (2003) Association between fruit and vegetables intake and change in body mass index among a large sample of children and adolescents in the United States. Int J Obes Relat Metab Disord 27, 821-826.

7. Lin BH \& Morrison RM (2002) Higher fruit consumption linked with lower body mass index. Food Rev 25, 28-32.

8. Trudeau E, Kristal AR, Li S et al. (1998) Demographic and psychosocial predictors of fruit and vegetable intakes differ: implications for dietary interventions. J Am Diet Assoc 98, 1412-1417.

9. Williams DE, Wareham NJ, Cox BD et al. (1999) Frequent salad vegetable consumption is associated with a reduction in the risk of diabetes mellitus. J Clin Epidemiol 52, 329-335.

10. US Department of Agriculture, Agricultural Research Service (2012) USDA National Nutrient Database for Standard Reference, Release 25. Nutrient Data Laboratory Home Page. http://www.ars.usda.gov/ba/bhnrc/ndl (accessed March 2013).

11. Institute of Medicine (2010) Strategies to Reduce Sodium Intake in the United States. Washington, DC: The National Academies Press.
12. US Department of Agriculture, Economic Research Service (2012) Diet Quality and Food Consumption: Food and Nutrient Intake Tables. http://ers.usda.gov/data-products/ food-consumption-and-nutrient-intakes.aspx (accessed March 2013).

13. US Department of Health and Human Services \& US Department of Agriculture (2005) Dietary Guidelines for Americans, 6th ed. Washington, DC: USDHHS and USDA; available at http://www.dietaryguidelines.gov

14. Centers for Disease Control and Prevention, National Center for Health Statistics (2005) National Health and Nutrition Examination Survey, 2003-2004. Atlanta, GA: CDC-NCHS; available at http://www.cdc.gov/nchs/nhanes/ wweia.htm

15. Moshfegh AJ, Rhodes DG, Baer DJ et al. (2008) The US Department of Agriculture Automated Multiple-Pass Method reduces bias in the collection of energy intakes. Am J Clin Nutr 88, 324-332.

16. Guenther PM, Reedy J, Krebs-Smith SM et al. (2007) Development and Evaluation of the Healthy Eating Index2005. Washington, DC: USDA, Center for Nutrition Policy and Promotion.

17. Bowman SA, Friday JE \& Moshfegh A (2008) MyPyramid Equivalents Database, 2.0 for USDA Survey Foods, 2003-2004. Washington, DC: USDA, Agriculture Research Service; available at http://www.ars.usda.gov/ba/bhnrc/fsrg

18. US Department of Human Health Services, National Institutes of Health \& National Heart, Lung, and Blood Institute (2006) Lowering Your Blood Pressure with DASH Eating Pattern. NIH Publication \#06-4082. Washington, DC: USDHHS, NIH and NHLBI; available at http://www. nhlbi.nih.gov/health/public/heart/hbp/dash/new_dash.pdf

19. US Department of Agriculture, Economic Research Service (2012) Vegetables and Pulses Data. http://ers.usda.gov/ data-products/vegetables-and-pulses-data.aspx (accessed September 2012).

20. Greene W (1990) Econometric Analysis. New York: MacMillan Publishing Company.

21. Mancino L, Todd J \& Lin BH (2009) Separating what we eat form where: measuring the effect of food away from home on diet quality. Food Policy 34, 557-562.

22. Wootan MG \& Vickory L (2012) Informed Eating: Calorie Labeling for Ready-to-Eat Food at Supermarkets and Convenience Stores. Washington, DC: Center for Science in the Public Interest; available at http://cspinet.org/new/ pdf/supermarket-labeling-report.pdf 